\title{
THE RESEARCH APPROACH AND METHODOLOGY USED IN AN INTERPRETIVE STUDY OF A WEB INFORMATION SYSTEM: Contextualizing Practice
}

\author{
Anita Greenhill \\ Manchester School of Management
}

\begin{abstract}
This paper contextualizes the research approach followed in an interpretive Information Systems study that explored the development of a Web information system. The paper provides details of the methodological approach followed in the project, the assumptions used, and the research techniques utilized when conducting a specific interpretive study of IS development. The aim of this paper is to provide a detailed presentation of the range of methods chosen to detail the rigor maintained in the research process associated with interpretive IS research. This paper illustrates how methods that are described as visual methodological techniques can be applied to an Information Systems study. With the presentation of this detail, it is hoped other IS researchers can reflect on their own practices when conducting interpretive research projects in comparison with those chosen for this project. The paper bridges the theoretical background of existing literature to illustrate how the exploration of method and research practice contributes to the examination of a chosen research topic.
\end{abstract}

Keywords: Method, interpretive study, space, visual techniques

\section{INTRODUCTION}

This paper extends the debate regarding appropriate methodological frameworks for the philosophy of science. Instead of weighing the suitability of individual methods, it details one study and its methodological practice. The study was qualitative, interpretive, critical, and asked, how do developers spatially perceive their Web information 
system? This focus also casts the project as an ontological exploration of the topic. The methodology pursued by the study makes a contribution to theory testing within the field of Information Systems but did not aspire to become a methodology for researching the spatial aspects of Information Systems. This paper presents the ontological and epistemological basis for the study. It reveals the assumptions that were embedded in the study and how these, in turn, informed methodological decisions regarding the project. This conceptualizes the use of specific methods by providing examples of data collected during original research. This paper contributes to the field of Information Systems research by illustrating the way interpretive methods enable detailed insight of Information Systems development.

The focus of the original study was on how information systems are spatially perceived by Web information system developers. The study focused on a team of Web publishers in a large government department in Australia who maintained an electronic publishing system. The team was developing a new Web information system for their publishing requirements. The research project provided insight into the internal operations of a large government department and its capacity to deal with the spatial forms that new technologies enable. The findings included an in-depth presentation of Web usage characteristics of the department. The primary informants of the study were described collectively as the Web development team. The research site was their workspace. The benefit of the original research lies with its detailed discussion of Web information systems development. The original study also included analysis of data gathered over a six-month period from in-depth observation and interviews that were conducted with team members regarding the new Web information system. The research offers descriptions of the socio-cultural and power relations in the organization that were reflected in the observed spatial configurations. The relationships conducted in the physical and virtual spaces of the organization being studied were described. None of these findings are presented in this paper. What is focused upon here is the relationship between the research project and the methods used to examine the topic of research. The paper specifically justifies the choice of the method finally utilized within the interpretive study.

\section{THE CASE METHOD AS A RESEARCH STRATEGY}

As a research strategy, the case method is used in situations where the purpose of research and its objectives are to find answers questions of how or what and to focus upon understanding the dynamics of an individual setting (Klein and Myers 1999; Yin 1989). The research incorporated descriptions and analysis from six months of in-depth observation and interviews concerning the organization's new Web information system. The research also described the power relations that were reflected by the spatial configuration of this unit through physical and virtual space allocations. The case study, as the name suggests, utilized a theory to explore a single case. In this way, the research detailed stories of what happened over a period of time between the people observed by the researcher. The study was empirical; however, it did not attempt to draw any positivist conclusions with the attendant requirements for identifying cause and effect in order to draw definitive findings. Interpretive research provides a mechanism to explore what those who were observed perceive to be an information system. The case study 
helps to understand if different socio-cultural experiences influence these perceptions. The research did not attempt to suggest that the way the research was interpreted is the only possible reading of this organization's new Web information system. The research undertook a thorough process of data gathering and, through a particular research lens, of detailing detail a particular situation.

It is important to stress that the examination of the information system was spatially oriented with an emphasis upon spatial configurations and not on other perspectives or phenomena. Emphasis was on locating the spatial dimensions to information sharing and the study sought to interpret the differences and similarities in the use of space.

\section{CONTEXTUALIZING THE STUDY BY DEFINING INFORMATION SYSTEMS}

Information Systems, as a discipline, is cross disciplinary. A broad research foundation provides the IS researcher with the best and worst aspects of its reference disciplines. As a result, there is no methodological uniformity within the discipline and intense debate over the methods employed to conduct information systems research continues (Benbasat et al. 1987; Checkland and Howell 1998; Kaplan 2001) and extends to the legitimacy of the discipline.

The range of perspectives that are IS necessitate the researcher to repeatedly and regularly contextualize their research by providing a definition of an information system within their work. For example, the study discussed in this paper used a combination of two definitions of IS to situate the research to the field as a whole. The first came from Keen (1980, p. 713), who states that information systems research should include the "study of effective delivery and usage of IS in organizations (and society)." The second definition used came from Galliers and Land (1987, p. 901), who identify information systems as being associated with the relations between "the organization and the people they serve." The context of this research project was clearly an IS study, as it considered the organization-wide issues of information system (a Web information system) and following Galliers and Land's extended definition, was also an exploration of the relationships held between the people and the system being studied.

The empirical aspects of the study examined space in the context of a Web information system.

[Space] is not simply inherited from nature, or passed on by the dead hand of the past, or autonomously determined by "laws" of spatial geometry as per conventional location theory. Space is produced and reproduced through human intentions, even if unanticipated consequences also develop, and even as space constrains and influences those producing it (Lefebvre in Molotch 1993, p. 887).

There is a growing number of studies concerning information systems and the World Wide Web (Eschenfelder and Sawyer 2001), the Internet (Bradley and Briggs 1995), and virtual reality (Robey et al. 2003; Truex and Baskerville 1998). The emphasis in the research considered here, however, differs from the assumptions of these previous 
studies. This research considered the spatial and socio-cultural work practices of individuals involved in the development of an information system. The work extends current spatially focused research in information systems by examining the usefulness of space for exploring new technologies, including the World Wide Web for information systems development.

\section{CONTEXTUALIZING THE RESEARCH}

The initial assumption of the research concentrated on the creation and utilization of space by the organization in the context of an information system. To this end the study considered whether a spatial consideration of information systems development was useful in its development. To achieve this, a detailed examination of organizational interactions was conducted to understand how information was developed by individuals for publication on the Web; how individuals differed in their socio-cultural position, technological context, and physical placement within the organization. The study also explored the similarities and differences between the social processes involved in the construction of space by asking how groups of people construct a shared understanding of a space. The research considered the combination of spatial, socio-cultural, and work practices of individuals involved in the development of an information system as these all contributed to its shared understanding.

This research aimed to produce an understanding of the context of information systems development (Walsham 1993, p. 58). The context for this research was an exploration of the social construction of space as it impacts on the development of a Web Information System. This research adapted Lefebrve's (1991) theory regarding the social production of space to explore whether spatial constructions are important to the development of workplace-based information systems. A spatial approach does not place primary emphasis upon the human aspects of the information system. What is privileged instead is the human construction of space. This emphasis is derived from the foundational assumption of the social construction of reality; we know the world only as we perceive it (Berger and Luckmann 1966). Social constructionism argues that our perceptions are based on learned interpretations of the world around us and that these learned interpretations are social. Berger and Luckmann also argue that we learn when we are engaged in social interaction. The main vehicles for conveying social meaning are symbols, cultural myths, the structure of our institutions and our rules for congruent action (pp. 55-56). These vehicles of meaning together construct our worldview, our sense of ourselves, our identity and purpose, as well as our ideologies. Our selves, our societies, and our institutions are consequently in a continual state of change through these interactions.

\section{CONSTRUCTIVIST RESEARCH}

This research project is located within the constructivist tradition. Constructivist ontologies aim to not reduce an observed research situation to generalizations but attempt to unfold context-specific patterns and tendencies (Karsten 2000). Constructivist research is always "irretrievably hermeneutic" (Giddens 1984). The subjects of the study, including the researcher, are influenced by, and influence, the research. 
Interpretations cannot be value-free but are subjective, multiple, and complex. The concern for bias in interpretive research is significantly different from that of scientific and realist approaches. In the social sciences, the subjective experience and presence of social agency including the researcher's own are focal points for the understanding of social phenomena (Boland 1991; Burrell and Morgan 1979; Giddens 1984; Hirschheim et al. 1995; Lee 1994; Trauth and Jessup 2000).

Interpretive epistemologies were utilized in the research (Klein and Myers 1996) to examine a Web information system (Van de Ven and Poole 1990; Walsham 1993). The research focused upon the observable cultural and historical aspects of the site with emphasis given to the spatial context of the developers and users of the information system. Central to this research was the identification of the organization's physical and virtual spatial environment. Therefore, it was necessary to draw heavily upon those methodologies associated with the visual domain of enquiry. Emmison and Smith (2000) describe visual enquiry as "the study of visibility, mutual interaction and semiotics as they relate to objects, buildings and people as well as to the study of images." They continue, "visual enquiry is no longer just the study of the image, but rather the study of the seen and observable." The application of visual methodological techniques to the study is expanded further in this paper.

\section{CONTEXTUALIZING THE RESEARCH PROCESS}

As this was a qualitative and critical study, particular assumptions were everpresent. These assumptions concerned the way the investigators understood the nature of reality, knowledge, human nature, and methodology, and the way that they interpret the research site (Pihlanto 1994). The assumptions in this research were founded around a subjectivity in which truth only exists through interlocking contextual understandings, and where reality is a subjective state of sensibility. These assumptions are based on the observation "that people create and associate their own subjective and intersubjective meanings as they interact with the world around them" (Orlikowski and Baroudi 1991, p. 24, citing Chua 1986). This research was an exploration of how truths can be found in social life which is itself socially constructed. If this assumption is pursued, then the social construction of these truths can inform both the participant and the researcher of their effect and presence. To clarify the research approach utilized in the original study, Orlikowski and Baroudi's framework has been adapted to illustrate the conduct of the research process (Table 1).

The research processes and their associated assumptions outlined in Table 1 informed and impacted upon the exploration of the research site. For example, contextual and ideographic methods were applied to enable the researcher to observe social practice to understand the Web development team's dynamic and conflictual development process. By applying a social construction of meaning with the data collected, a number of targeted questions could be asked of the development team. It was intended that the research would reveal how this team spatially perceived their Web Information System. This would then inform the Web development team and their employer of how an informed outsider saw their organizational processes. This was appealing to the department as there was an economic agenda regarding the funding of the Internet development. 
Table 1. Description of the Properties and Patterns of the Study

\begin{tabular}{|c|c|c|}
\hline Beliefs About & Explanation & This Research \\
\hline \multicolumn{3}{|l|}{ Physical and social reality } \\
\hline Ontology & $\begin{array}{l}\text { Whether social and physical } \\
\text { worlds are objective and } \\
\text { exist independently of } \\
\text { humans, or subjective and } \\
\text { exist only through human } \\
\text { action }\end{array}$ & $\begin{array}{l}\text { Subjectivist,constructionist } \\
\text { at least when regarding } \\
\text { social reality }\end{array}$ \\
\hline Human Rationality & $\begin{array}{l}\text { Theinternationality } \\
\text { ascribed to human action }\end{array}$ & $\begin{array}{l}\text { Agency as ability to do } \\
\text { otherwise }\end{array}$ \\
\hline Social Relations & $\begin{array}{l}\text { Whether social relations are } \\
\text { intrinsically stable and } \\
\text { orderly, or essentially } \\
\text { dynamic and conflictual }\end{array}$ & $\begin{array}{l}\text { Dynamic and often } \\
\text { conflictual }\end{array}$ \\
\hline \multicolumn{3}{|l|}{ Knowledge } \\
\hline Epistemology & $\begin{array}{l}\text { Criteria for constructing and } \\
\text { evaluating knowledge }\end{array}$ & $\begin{array}{l}\text { Interpretive, intersubjective, } \\
\text { Hermeneutic }\end{array}$ \\
\hline Methodology & $\begin{array}{l}\text { Which research methods are } \\
\text { appropriate for generating } \\
\text { valid evidence }\end{array}$ & $\begin{array}{l}\text { Contextualist, ideographic } \\
\text { methods }\end{array}$ \\
\hline $\begin{array}{l}\text { Relationship between theory } \\
\text { and practice }\end{array}$ & $\begin{array}{l}\text { The purpose of knowledge } \\
\text { in practice }\end{array}$ & To inform and to enlighten \\
\hline
\end{tabular}

\section{METHODOLOGICAL APPROACHES}

A critical approach was applied to each theme in the project including space, organizations and information systems, the developers, information systems and work spaces, the Web, and virtual reality. The study challenged the limited understandings of the spatial qualities of information systems and the limited regard of space by developers and users in relation to information systems development. Orlikowski and Baroudi (1991, p. 24, citing Chua 1986) explain that

Critical studies aim to critique the status quo, through the exposure of what are believed to be deep-seated, structural contradictions within social systems, and thereby to transform these alienating and restrictive social conditions.

Space is a socially constructed phenomenon. If the socio-cultural aspects of reallife space are ignored, then virtual space and all spaces of occupation become problematic. This was an issue for this research as it examined the spaces associated with a Web information systems and whether physical restrictions are experienced in virtual reality based systems as they are in real-life systems. As a result, an aspect of the study was to examine if the development and usage of a Web information system would also be experienced in the same way. 
Specific methodological choices had to be made in the study for their capacity to meet the demands of the theory. Theory, in this way, determined and directed method. Lefebvre (1991) emphasizes that space should be examined using the broad dichotomy of social and abstract space. Social space is, therefore, further categorized as spatial practice, representations of space, and representational space. The researcher can include observation of textures, shapes, groupings of objects, creative expressions like drawings and even memories (Bachelard 1969, p. 6; Game 1995, p. 201). Consequently, emphasis is placed upon the spatial dimensions of information sharing, interplay, and grouped according to the overarching concepts of social space. Data was gathered relating to each individual category of social space and then analyzed separately. To capture spatial data it was necessary for methodological choices to be broad enough to encapsulate this triplicate analysis. Each data collection configuration was identified and discussed in relation to the appropriate theoretical lens in the analysis phase of the research project.

\section{CHOOSING THICK DESCRIPTION AS A METHODOLOGICAL APPROACH TO DATA COLLECTION}

The most significant methodological practice followed throughout the study was thick description. Thick description is underutilized in contrast to ethnography within qualitative approaches to information systems exploration (Myers 1999; Trauth 2000; Trauth and Jessup 2000). The significance of ethnography, for the field of Information Systems and for qualitative analysis generally, is in its ability to present an intensive study of a particular social phenomenon (Trauth 2000; Trauth and Jessup 2000). However, the research conducted for this study was not a ethnography or an interpretive in-depth case study, as it is described by Walsham (1993). Instead it drew upon the research foundations articulated in anthropology by utilizing an ethnographic approach to data collection in a manner that Geertz (1973) describes as "thick description." Schultze (2001, p. 90) states that "the ethnographic method requires the researcher to closely observe, record, and engage in the daily life of people in the field and write about it in descriptive detail." In this respect, both ethnography and thick description utilize a similar impetus. A broad range of data-gathering techniques are drawn upon as well as the intuitive and interpretive skills of the researcher in order to conduct research. The significant difference between ethnography and thick description is the duration of time spent at the research site (Klein and Myers 1999). Ethnography calls for extensive interaction over time to fully immerse the researcher in the culture in order to reduce the bias of observations and to give a less tainted account of the subjects of observation (Atkinson 1990; Daniel and Peck 1996, p. 21; Hughes et al. 1999). Thick description also aims at rich and full descriptions of a particular research site that is not linked to a time frame. Instead it has the objective of providing a thorough, careful, and accurate exploration of the lived experiences of the research subjects as they have been observed by the researcher (Atkinson 1990, p. 8; Geertz 1996). For example, data gathered regarding the informant's daily activities and utilizing a thick description focus appeared as such: 
Crystal walks over to Cassandra's cubicle. Cassandra's cubicle backs onto Crystal's but as an indication of her higher organizational rank Cassandra occupies a cubicle to herself. Cassandra's cubicle is her own personal space, rectangular in shape and fitted out with the departmental standard grey and beige furnishings. Crystal enters Cassandra's cubicle and asks if they can talk about the day's activities. Crystal in her debriefing keeps Cassandra informed on what she and Penny have discussed and agreed to do today. Crystal tells Cassandra that Penny will contribute to the resolution of the file size issue and the construction of the office map.

The depth and detail of the observations recorded by this method offers an account that maintains an unbiased interpretation of the events observed solely through the researcher's own expertise and sensitivity to the research subject. To achieve this objectivity, the study presented a narrative of the spatial interactions of the Web development team. A chronology provided a thick and detailed description of their daily activities and experiences. The narrative did not disentangle time or space; instead it provided an immediate description of the worker's daily life. To convey the depth and complexity of ethnographic studies, the description was offered in the narrative form truest to the ethical imperative of the writer and the multitude of representations the subject reveals in a research context (Barthes 1983). In this way, the researcher's narrative of interactive events at the research site provides additional detail to the observations.

\section{REFLECTING ON CHOICE OF QUALITATIVE METHOD}

Trauth's discussion of the influences on the choice of qualitative methods in information system research is utilized here. Trauth (2001, pp. 4-11) poses five influences regarding the choice of qualitative analysis. The five influences are the research problem, the researcher's theoretical lens, the degree of uncertainty surrounding the phenomenon, the researcher's skills, and contemporary academic politics.

\subsection{Research Influence 1: The Research Problem}

The initial assumption for the research concentrated on the creation and utilization of space by the organization within the context of an information system. To this end the study considered whether a spatial consideration of information systems development was useful during the development of that information system. To achieve this, a detailed examination of organizational interactions was conducted to understand how information was developed by individuals for publication on the Web; how individuals differed in their socio-cultural position, technological context, and physical placement within the organization. The objective of the research was to understand the significance of space within information systems development. The study extended current spatially focused research in Information Systems by examining the usefulness of space for exploring new technologies. Significantly, for this analysis, a clear picture 


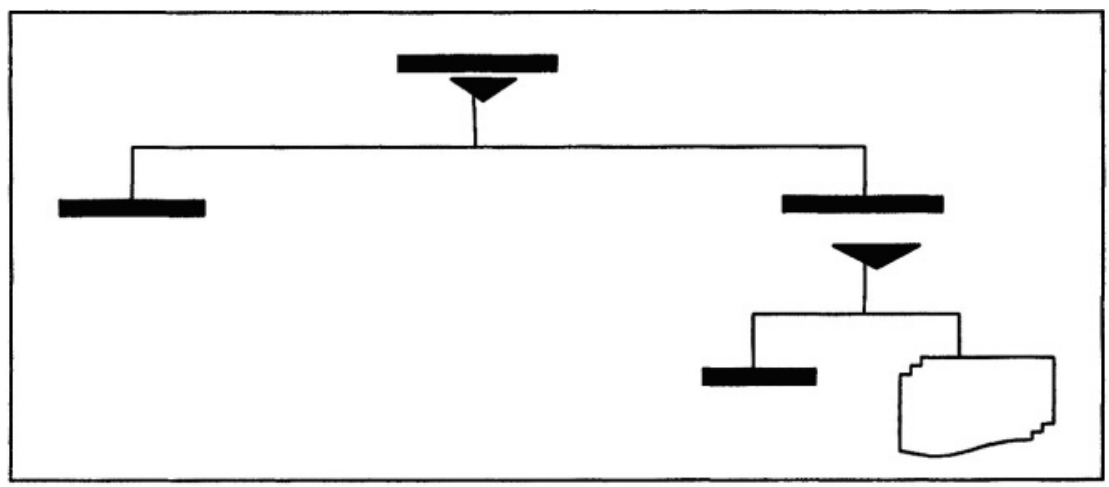

Figure 1. Diagram Taken from System Specification Document

of the Web development team's understanding of the system was provided by their technical documentation. Figure 1 came from an illustration included in the functional specifications documents that had been drawn up by an outside contractor and presented to the Web development team. This particular example provides a detailed pictorial representation of the Web information system subsystem that was to be developed to store and maintain information about news, events and other system generated events.

The drawing was used by the designers to illustrate to the team where they understood specific information would be positioned within the new Web site. This diagram is also a site map. It uses pages and lines to indicate general connectivity between the pages of the Web site. It symbolizes the connectivity of buttons and hypertext links. This is represented as the small arrows in the picture and indicates links between related pages. Each page has a series of links. Spatial references were collected and observed during all aspects of the research but it was only with the analysis and collation of this data that the significance of spatiality to the development process was revealed.

\subsection{Research Influence 2: Researcher's Theoretical Lens}

Lefebrve's primary argument is that space and the social construction of space are not always easily observed. However, he claims that they are important considerations for research. An appreciation of social space can, therefore, only be achieved through the exploration of the subjective position (Lefebvre 1991, p. 6). The thick description approach to ethnography was adopted because it is through analysis of the data gathered about the languages, images, institutional practices, and other social practices discerned in the primary research that questions about space and the development of a Web information system could be explored. Another example drawn from the research is the interview transcript and complimentary discussion offered by the researcher:

I think of it in a similar way as there being a pool of documents. I think of it more hierarchical in a way. You have a large pool of documents all sitting in 
a big pond at the bottom, sort of at a level. You have the home page right at the top, and then you have these intermediate pages in between, which are like menu pages that help to sort and give access to the big pool at the bottom....they're dynamically done, so I might choose to create a intermediary menu page that's on the theme... and then by tagging all the documents [the pages] on the bottom, they automatically appear on the menu....It's never completely hierarchical but that's a general way to get a grip on the information.

This example shows the usefulness of thick description and non-participant observation as an appropriate way to explore the research site's socio-cultural, technical, and historical makeup.

To adequately address the central research problem regarding space in information systems development it was also necessary for a critical ethnographic approach (Bentley et al. 1992, p. 123). Lefebrve states that space is an integral component within the circuits of capitalism, and therefore contributes to the perpetuation of workers' inequality. It was necessary, in the framework of this claim, to explore the existing power structures of the research site. Immersive techniques allow critical explorations to uncover the forms of these interactions (Schultze 2001, p. 80). The immersed researcher can provide the depth of analysis necessary to explore social phenomena such as space. The researcher, at appropriate periods of observation, sketched the spatial surroundings of the working environment. One example is presented in Figure 2.

The use of an ethnographic technique was chosen because this method was most suited to revealing "the story behind the space" of a Web information system from the developer's perspective. This method enabled the researcher to observe the daily events of a group of people working on developing a Web information system. Research activities included observing the people and the events and included mundane elements of a working team's daily lives. For example, detailed observation from the data collection existed in this form:

I look at my watch. It is 9:00 a.m. The office was quickly filling with people. They all began observing their morning work preparation rituals: starting up their computers, planning their day's activities, greeting those around them, collecting coffees, sharing tales and salutations, "Good morning Mike, how was your weekend?" Nigel spotted me, and after extending the usual welcoming remarks, introduced me to a number of the people in the Web development team. Nigel was the acting project manager. He is a thin, wiry man whose age and length of experience is very hard to ascertain. His indefiniteness is heightened by the impact of his very white bleached hair with dark roots, his weathered complexion, and his crisp mannerisms.

This method of data collection provides a different understanding of the working environment than those that can be revealed by a questionnaire or other methods.

The ability to experience the team's daily life in its totality was restricted by the organization and the research focus itself. It was necessary to consider the speed with which this form of technology was evolving and being embraced by the organization. As a consequence, an elongated observation period covering a number of years risked 


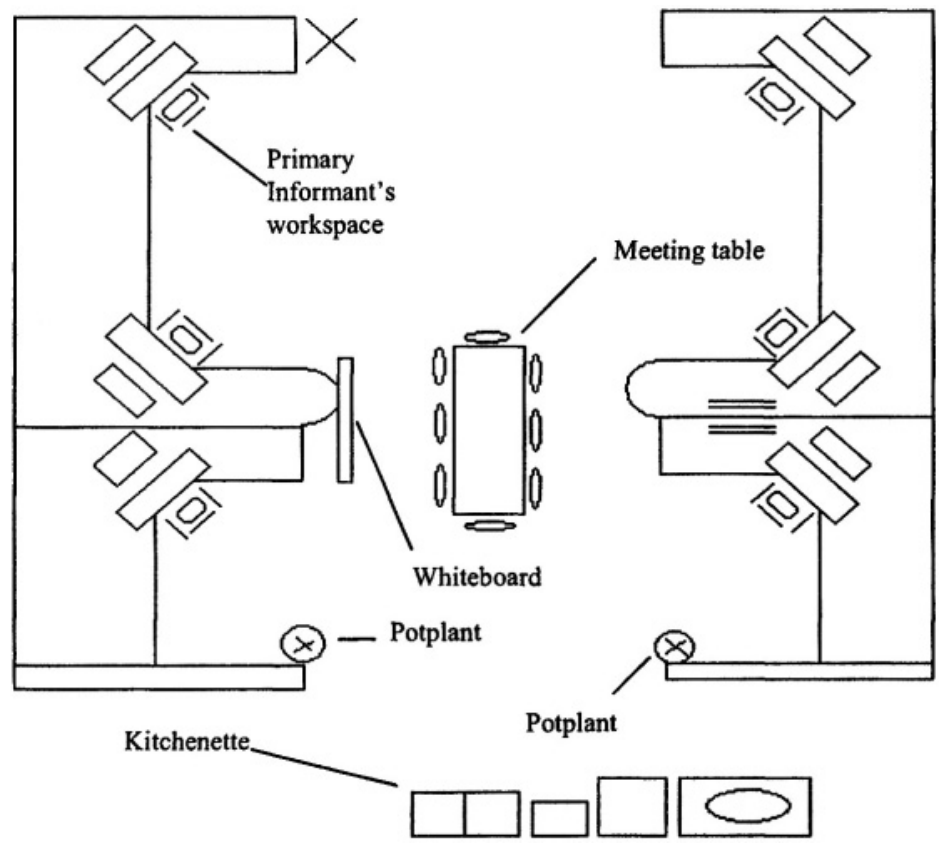

Figure 2. Diagram of the Primary Informant's Work Area

encountering new impetus and changes in direction brought with the introduction of still newer Web technologies. Utilizing a more time consuming approach would result in a lack of accounting for the immediacy of the development. The project itself was already behind schedule and the excessive demands on the host organization meant that a prolonged period of in-depth observation of a specific team member could not be sustained for more than one week. Although the organization supported the research it could not sustain a drawn-out research protocol.

\subsection{Research Influence 3: Degree of Uncertainty}

There was a high degree of uncertainty surrounding the phenomena under study. An example of this uncertainty can be discerned from the data that the interviews and informants themselves provided.

The information often just comes in as, say, a raw manuscript, if you're backing a print with it. I mean, it's just a raw manuscript with the author editing it. Initially when we started off over 3 years ago now, we thought we could train the staff out there how to create HTML pages. It is high technology and they're not all DAP people, are not capable of doing the work required [to 
put it online]. You know, to take it to print, you get the raw manuscript and take it through the publishing process to look at what comes out the other end.

The exploration of the social construction of space and the perceptions of the developers and users of the Web information system represents the intangible dimensions of an information system. Other studies into space and information systems utilize geographic constructs or artifactual assessments of the information system environment. The exploration of the socio-cultural impact brought by the people engaging with the Web information system has a high degree of uncertainty associated with it. There was no existing documentation or description about any of the people studied or, in a general sense, how the developers of a Web information system spatially perceive their system. The study utilized visual data collection in the form of photography to help clarify the spatial dimensions of organizational practices.

The approach to data collection required an open mind and acceptance of the fact that the informants would reveal their own particular socio-cultural perspectives and biases. In this way, the what of the theory drove the how associated with the method of this research project (Järvinen 1999; Trauth 2001). To minimize the degree of uncertainty of the phenomenon being studied, appropriate methods had to be utilized to explore how the developers and users spatially perceived a Web information system. This was done by drawing on the researcher's own interpretation of the research site and by employing a critical eye to delve beyond the immediately obvious interactions. This approach contrasts with a quantitative exploration of a Web information system's spatiality. A quantitative method would need to establish the reality of such a statement. To do this, the researcher might measure the volume of traffic on the Web sites or measure the distance between individuals working on the Web information system and then assess the extent that this is a significant space to traverse. However, the focus of this research project was to explore the sociality of an information system through an ethnographic approach aiming to detail spatial perceptions, and their existence. Using a variety of qualitative techniques as an interpretive foundation the finalized study was able to reveal that the Web development team did hold specific perceptions about the Web pages contained on their Web site. These perceptions predominantly existed as an awareness of the page as a bounded box and these visualizations were revealed through descriptive passages relating to the Web information system itself. The information contained on the Web site was also described as contained and bounded. For example, Crystal used metaphor to explain how she mentally visualizes the site.

There's usually some sort of categorizing and clustering of things, there's usually some sort of overarching framework that you can use that means it can be contained with one page. In terms of the Internet and what's happening with the Internet, this is a really old sort of interface.

I think of it in a similar way as there being a pool of documents. I think of it more hierarchical in a way. You have a large pool of documents all sitting in a big pond at the bottom, sort of at a level. You have the home page right at the top, and then you have these intermediate pages in between, which are like menu pages that help to sort and give access to the big pool at the bottom.... 
they're dynamically done, so I might choose to create a intermediary menu page that's on the theme....and then by tagging all the documents [the pages] on the bottom, they automatically appear on the menu....It's never completely hierarchical but that's a general way to get a grip on the information.

This example provides some insight into the visual image that Crystal had about the Web and the Web information system itself. Chorafas and Steinmann (1995, pp. 206-7) see visualization as a means to discovering users' understanding of technology. In this way, drawing upon ethnographic methods allowed the researcher to go beyond understanding the technology to explore the how element of spatial perception.

\subsection{Research Influence 4: Researcher's Skill}

The foundations for the research topic and interest in the area of virtual space grew out of earlier research in the field of anthropology and sociology. An extensive history associated with the use qualitative methods led to the decision to use an array of qualitative methods that was not restricted to a narrow range of method. Having studied many methods, with significant practical experience of qualitative studies, and experience as a market researcher, I had practiced a variety of methodological techniques over the previous eight years. The methods I had used ranged from the development and usage of nationwide survey instruments, to psychological and behavioral market research practices, to undercover research evaluation of retail business practices, as well as many one-to-one in-depth interviewing and group interviewing sessions. At no time was the prospect of using interpretive methods to explore the notion of perceived space intimidating. I also had an established interest in computing, multimedia and World Wide Web related technologies.

\subsection{Research Influence 5: Contemporary Academic Politics}

I have a Bachelor of Arts with Honors and this provides me with a strong theoretical and analytical understanding relating to the social practices of computer usage. The academic political climate in Australia in the late 1990s also played a significant role in my choice to explore other research projects that examine the social impact of networking. The degradation of the Humanities and Arts Faculties in terms of guaranteed employment, funding, and job certainty for new academics (Keen 2001) seemed to lead naturally to the more secure field of information systems, where jobs were relatively abundant with a degree of job security. From this stable academic environment, a research focus regarding computers and society focusing on Web Information Systems was concretized.

In the context of the wider academic political environment there is also acknowledgment by other disciplines that a need exists for more critical research regarding Information Systems and embracing Web technology by the mainstream. The intended audience for this research was fellow researchers and academics situated within the Information Systems field, although it was, and is, hoped that others may also show interest in this cross-disciplinary field. 


\section{DATA COLLECTION AND ANALYSIS IN AN INTERPRETIVE STUDY}

Data collection in thick description often incorporates a number of techniques to capture the breadth of activity being observed. The data collection for this research project used a single case study with a variety of collection techniques over two specific periods. To ensure that a chain of evidence could be adhered to, the research conduct was divided into phases.

Exploratory research was conducted in the first phase of research. This was undertaken with a series of semi-structured interviews with managerial level staff within the department. Three employees who worked directly under these managers were also interviewed to provide alternative sources and stories to those presented by the managers. This was done to include the many levels of the workplace hierarchy. All of the informants interviewed in phase I were identified as people responsible for the maintenance and development of the organization's Web sites. The questions put to them encompassed a range of issues including questions about personal interactions, work practices, and specific spatial understanding. The initial interviewing provided clues as to where further detail could be built upon to explore the core research question associated with Information Systems development. More visually oriented techniques such as the field diary, hand-drawn sketches, and digital photographs were expanded upon in later research phases. Table 3 provides details of all of the types of data or information sources that were gathered in the context of this particular study. It shows the variety of types of information that can be collected from a research site.

Significantly, in all research studies data analysis is undertaken to examine, categorize, and assess what has been revealed by a particular set of data. This research project has, in a manner similar to that of Heaton (1998), utilized interpretive methods to gather data through nonparticipant observation, a research diary, interviews, and documentation. The choice of these methods was influenced by the desire to explore the socio-cultural understandings of the informants and how they reflect their own understandings in the design of an information system. The research diary, taped debriefings, sketches, and other narrative descriptions and observations were kept as integral elements of thick description of the research site. The structure of the field diary is shown in Table 4.

The field diary was a significant tool in this study as it enabled the researcher to clearly and consistently observe and document the interactions that were occurring at the time of the study. Ad hoc data gathering could not achieve the detail that a consistent field diary can achieve. It is also important to note, as van Maanen (1988, p. xi) has said, that discussions relating to method and particularly ethnographic methods should always

explicitly consider (1) the assumed relationship between culture and behavior (the observed); (2) the experience of the fieldworker (the observer); (3) the representational style selected to join the observed (the tale); and (4) the role of the reader engaged in the active reconstruction of the tale (the audience). 
Table 2. Phases of the Research Conduct

\begin{tabular}{|c|c|c|}
\hline Phase & Description & Timetable \\
\hline I & Formation of the theoretical framework. & May 1998 \\
\hline II & $\begin{array}{l}\text { Cooperation with DAP begins. } \\
\text { First exploratory interviews begin. } \\
\text { Interviews conducted with Alison, Kent, Brock, Diane, } \\
\text { George, and Nigel. } \\
\text { Written material collection begins. } \\
\text { Material includes booklets and pamphlets released to } \\
\text { general public, internal documents including corporate } \\
\text { structure, aims and objects, internal policies corporate } \\
\text { image, documents on technical training programs, print- } \\
\text { outs from intranet internal announcements, general site } \\
\text { layout of intranet, Internet information printouts. } \\
\text { Analysis of potential leads for second phase study occurs. }\end{array}$ & October 1999 \\
\hline III & $\begin{array}{l}\text { Collection of second round interviews begins. } \\
\text { Interviews with the manager of the Web development } \\
\text { team. } \\
\text { Portia (Nigel interviewed in phase I). }\end{array}$ & December 1999 \\
\hline IV & $\begin{array}{l}\text { Collection of interviews continues. } \\
\text { Participant observation (one week period) shadowing } \\
\text { Crystal. } \\
\text { More documentation collected including meeting agendas, } \\
\text { newspaper articles from the site, systems development } \\
\text { documents, organizational charts and maps, documents on } \\
\text { proposed amendments to the systems, copies of e-mails, } \\
\text { change request forms, systems development time lines and } \\
\text { costs, information flow diagrams both formal and } \\
\text { informal, progress reports, more Web pages relating to site } \\
\text { development and construction, functional specification } \\
\text { documents of new system, secondary research site } \\
\text { background documents from the Web. } \\
\text { Further interviews with Web development team including } \\
\text { Roger, Penny, and Crystal. } \\
\text { Interviews conducted with two Ping employees: Manny } \\
\text { (the lead technical developer) and Cain (back end or } \\
\text { systems developer). }\end{array}$ & April 2000 \\
\hline $\mathrm{V}$ & $\begin{array}{l}\text { Final data collection ready for analysis. } \\
\text { Pattern matching. } \\
\text { Coding and exploration of transcripts. } \\
\text { Coding and exploration of field notes and diary. } \\
\text { Analysis of written documentation. }\end{array}$ & July 2000 \\
\hline VI & $\begin{array}{l}\text { Confirmation of interpretation and analysis with research } \\
\text { site. E-mail interactions. }\end{array}$ & September 2000 \\
\hline VII & Research results ready for reporting. & May 2001 \\
\hline
\end{tabular}


Table 3. Information Sources Used in the Study

\begin{tabular}{|l|l|l|}
\hline \multicolumn{1}{|c|}{ Information Source } & \multicolumn{1}{|c|}{ Form of Materials } & \multicolumn{1}{|c|}{$\begin{array}{c}\text { Period } \\
\text { Collected }\end{array}$} \\
\hline Formal documentation & $\begin{array}{l}\text { Printed material ranging from memoranda to } \\
\text { minutes of meetings to formal reports and Web } \\
\text { site pages. }\end{array}$ & $\begin{array}{l}\text { Phase II, } \\
\text { Phase IV }\end{array}$ \\
\hline $\begin{array}{l}\text { Archival and historical } \\
\text { records }\end{array}$ & $\begin{array}{l}\text { Organizational charts, financial and personal } \\
\text { records, maps, graphs and service statistics. }\end{array}$ & $\begin{array}{l}\text { Phase I, } \\
\text { Phase II, } \\
\text { Phase IV }\end{array}$ \\
\hline Informal documentation & $\begin{array}{l}\text { Hand-drawn material ranging from sketches on } \\
\text { white boards to scribbles and notes to other } \\
\text { employees or self. }\end{array}$ & $\begin{array}{l}\text { Phase II, } \\
\text { Phase IV }\end{array}$ \\
\hline Interviews & $\begin{array}{l}\text { Open-ended and semi-structured interviews } \\
\text { coupled with probing questions. }\end{array}$ & $\begin{array}{l}\text { Phase II, } \\
\text { Phase IV }\end{array}$ \\
\hline $\begin{array}{l}\text { Direct or participant } \\
\text { observation }\end{array}$ & $\begin{array}{l}\text { Absorbing and noting details, actions, and } \\
\text { subtleties of the field environment. }\end{array}$ & Phase IV \\
\hline Physical artifacts & $\begin{array}{l}\text { Office and room construction, chairs tables, } \\
\text { office cubicles, etc. }\end{array}$ & $\begin{array}{l}\text { Phase II, } \\
\text { Phase III, } \\
\text { Phase IV }\end{array}$ \\
\hline
\end{tabular}

Table 4. Layout of Field Diary: Tuesday, April 4

\begin{tabular}{|c|l|l|}
\hline \multicolumn{1}{|c|}{ Time } & \multicolumn{1}{|c|}{ Action } & \multicolumn{1}{|c|}{ Interpretation } \\
\hline 9:20 a.m. & Spoke for a while. & $\begin{array}{l}\text { Takes a while to up load. Mixture of } \\
\text { messages. Their own e-mails and chat } \\
\text { group. }\end{array}$ \\
\hline 9:31 a.m. & Turned computer on. & $\begin{array}{l}\text { Problem is with someone she has } \\
\text { trained - Cascade I style sheet } \\
\text { (enabled). }\end{array}$ \\
\hline 9:43 a.m. & $\begin{array}{l}\text { Telephones woman to check out } \\
\text { problem. }\end{array}$ & $\begin{array}{l}\text { Sarah is not quite sure why, then gets an } \\
\text { idea. Will relink pages. Cascade needs } \\
\text { linking. File size is too long - strip down } \\
\text { file size (html). She leaves it to test or } \\
\text { keep playing with it at a later date. } \\
\text { It works; problem is solved. She gives } \\
\text { more advice to change the different } \\
\text { directories. }\end{array}$ \\
\hline
\end{tabular}


Consistency in the data gathering techniques followed by the researcher regardless of their qualitative or quantitative foundations should adhere to these considerations. In this particular study, these sentiments were adopted and choosing visually, spatially oriented methods of data collection were selected to reinforce the spatial dimensions of the theoretical focus of the study.

\section{CONCLUSION}

This paper has contextualized a recent research project by outlining its method and process. The definitions given by Keen (1980) and Galliers and Land (1987) are used to contextualize the foundational assumptions that define an information system. A combination of these two definitions was used to include and situate human relationships within the information system studied. The methodological approach, assumptions used, and the research techniques are presented to reveal the way in which a qualitative, interpretive, and critical research project has been conducted. Considerable explanation has been provided about the epistemological, ontological, and theoretical positions pursued in this study. This situates the research in contrast to other research of similar topics. This paper clarifies how and why theoretical choices are made in research. Theory often informs the methodological practices the research must use to explore an interpretive study at a chosen research site. This paper provides an overview of one form of qualitative research in information systems. It argues that the primary research question is the hook on which all research approaches and methodological decisions rest. Because the research was ontological and theory testing was emphasized, ethnographic analysis in the form of thick description has been presented as the most appropriate method with which to conduct this research. A variety of data gathering techniques including visual techniques and the necessity of a field diary for consistency are discussed to illustrate the maintenance of rigor in such studies.

\section{REFERENCES}

Atkinson, P. The Ethnographic Imagination: Textual Constructions of Reality, London: Routledge, 1990.

Bachelard, G. The Poetics of Space, Boston: Beacon Press., 1969.

Barthers, R. "Barthes: Selected Writings," in S. Sontag (Ed.), Douglas, Isle of Man: Fontana Press, 1983.

Benbasat, I.; Goldstein, D. ; and Mead, M. "The Case Research Strategy in Studies of Information Systems," MIS Quarterly (11:3), September 1987, pp. 369-387.

Bentley, R. H.; Randall, J.; Rodden, D.; Sawyer, T.; Shapiro, D.; and Sommerville, I. "Ethnographically-Informed Systems Design for Air Traffic Control," in J. Tuner and R. Kraut (Eds.), Proceedings of the Computer Supported Cooperative Work Conference, Lancaster, UK, 1992.

Berger, P. L., and Luckmann, T. The Social Construction of Reality: A Treatise in the Sociology of Knowledge, New York: Anchor Books, 1966.

Boland Jr., R. "Information System Use as a Hermeneutic Process," in H-R. Nissen, H. Klein, and R. Hirschheim (Eds.), Information Systems Research: Contemporary Approaches and Emergent Traditions, Amsterdam: North-Holland, 1991, pp. 439-458. 
Bradley, M. P., and Briggs J. S. “An Internet Information System for GP's," Information Research: An Electronic Journal, 1995 (available online at http:// InformationR.net/ir/33/paper41.html).

Burrell, G., and Morgan G. Sociological Paradigms and Organizational Analysis, Aldershot, England: Gower Publishing Company Ltd., 1979.

Checkland, P., and Howell, S. Information, Systems and Information Systems: Making Sense of the Field, Chichester, UK: Wiley, 1998.

Chorafas, D. N., and Steinmann, H. Virtual Reality: Practical Applications in Business and Industry, Englewood Cliffs,NJ: Prentice-Hall, 1995.

Chua, W. "Radical Developments in Accounting Thought," Accounting Review (61), 1986, pp. 583-598.

Daniel, E. V., and Peck J. M. "Culture/Contexture: An Introduction," in E. V. Daniel and J. M. Peck (Eds.), Culture/Contexture: Explorations in Anthropology and Literary Studies, Berkeley, CA: University of California Press, 1996.

Emmison, M., and Smith, P. Researching the Visual, London: Sage Publications, 2000.

Eschenfelder, K., and Sawyer, S. "Web Information Systems Management: Proactive or Reactive Emergence,” in N. L. Russo, B. Fitzgerald, and J. I. DeGross (Eds.), Realigning Research and Practice in Information Systems Development: The Social and Organizational Perspective, Boston: Kluwer Academic Publishers, 2001, pp. 163-181.

Galliers, R., and Land, F. F. "Choosing Appropriate Information Research Methodologies," Communications of the ACM (30:11), 1987, pp. 900-902.

Game, A. "Time, Space, Memory, with Reference to Bacheland" in M. Featherstone, S. Lash, and R. Robertson (Eds.), Global Modernities: From Modernism to Hypermodernism and Beyond, London: Sage Publications, 1995, pp. 192-208.

Giddens, A. The Constitution of Society, Cambridge, MA: Polity Press, 1984.

Geertz, C. Thick Description: Toward an Interpretive Theory of Culture, New York: Basic Books Inc., 1973.

Geertz, C. "The World in a Text: How to Read Tristes Tropiques," in E. V. Daniel and J. M. Peck (Eds.), Culture Contexture: Explorations in Anthropology and Literary Studies, Berkeley, CA: University of California Press, 1996.

Heaton, L. "Talking Heads vs. "Virtual Workspaces: A Comparison of Design Across Culture," Journal of Information Technology (13:4), 1998, pp. 259-272.

Hirschheim, R.; Klein, H. ; and Lyytinen, K. Information Systems Development and Data Modeling: Conceptual and Philosophical Foundations, Cambridge, UK: Cambridge University Press, 1995.

Hughes, J.; O’Brien, J.; Randall, D.; Rouncefield, M.; and Tolmie, P. "Virtual Organizations and the Customer: How 'Virtual Organizations' Deal with 'Real' Customers," in Proceedings of the $4^{\text {th }}$ United Kingdom Association of Information Systems (UKAIS) Conference, University of York, 1999.

Järvinen, P. On Research Methods, Tampere, Finland: Tampereen Yliopistopaino Oy, JevenesPrint, 1999.

Kaplan, B. "Evaluating Informatics Applications-Some Alternative Approaches: Theory, Social Interactionism, and Call for Methodological Pluralism," International Journal of Medical Informatics (64), 2001, pp. 39-56.

Karsten, H. "Constructing Interdependencies with Collaborative Information Technology," in R. Baskerville, J. Stage, and J. I. DeGross (eds.), Organizational and Social Perspectives on Information Technology, Boston: Kluwer Academic Publishers, 2000, pp. 429-450.

Keen, P. G. W. "MIS Research: Reference Disciplines and Cumulative Tradition," in E. R. McLean (Ed.), Proceedings of the First International Conference on Information Systems, Philadelphia, PA, 1980, pp. 9-18. 
Keen, S. "Economics: From Emperor to Vassal?," Australian Universities Review (44), 2001, pp. 1-2, 15-17.

Klein, H. K., and Myers, M. D. "A Set of Principles for Conducting and Evaluating Interpretive Field Studies in Information Systems," MIS Quarterly (23:1), 1999, p. 67-93.

Klein, H., and Myers, M. "The Quality of Interpretive Research in Information Systems," Working Paper Series, Binghamton University, School of Management, Binghamton, New York, 1996.

Lee, A. S. "The Hermeneutic Circle as a Source of Emergent Richness in the Managerial Use of Electronic Mail," in J. I. DeGross, S. L. Huff, and M. C. Munro (Eds.), Proceedings of the $15^{\text {th }}$ International Conference on Information Systems, Vancouver, Canada, 1994, pp. 129140.

Lefebvre, H. The Production of Space, Oxford: Blackwell, 1991.

Molotch, H. "The Space of Lefebrve." Theory and Society (22), 1993, p. 887-895.

Myers, M. E. "Qualitative Research in Information Systems," IS World, 1999, (available online at http://www.qual.auckland.ac.nz/).

Orlikowski, W. J., and Baroudi J. J. "Studying Information Technology in Organizations: Research Approaches and Assumptions," Information Systems Research (2:1), 1991, pp. 1 -28.

Pihlanto, P. "The Action-Oriented Approach and Case Study Method in Management Studies," Scandinavian Journal of Management (10:4), 1994, pp. 369-382.

Robey, D.; Schwaig, K. S.; and Jin, L. "Intertwining Material and Virtual Work," Information and Organization (13), 2003, pp. 111-129.

Schultze, U. "Reflexive Ethnography in Information Systems Research," in E. M. Trauth (Ed.) Qualitative Research in IS: Issues and Trends, Hershey, PA: Idea Group Publishing, 2001.

Trauth, E. M. The Culture of an Information Economy, Dordrecht: Kluwer Academic Publishers, 2000, pp. 78-103.

Trauth, E. M. Qualitative Research in IS: Issues and Trends, Hershey, PA: Idea Group Publishing, 2001.

Trauth, E. M., and Jessup, L. "Understanding Computer Mediated Discussions: Positivist and Interpretive Analyses of Group Support System Use," MIS Quarterly (24:1), 2000, pp. 4379.

Truex, D., and Baskerville, R "Deep Structure or Emergence Theory: Contrasting Theoretical Foundations for Information Systems Development," Information Systems Journal (8:3), 1998, pp. 99-118.

Van de Ven, A. H., and Poole, M. S. "Methods for Studying Innovation Development in the Minnesota Innovation Research Program," Organization Science (1:3), 1990, pp. 13-335. vanMaanen, J. Tales of the Field, Chicago: University of Chicago Press, 1988.

Walsham, G. Interpreting Information Systems in Organizatons, Chichester, UK: Wiley, 1993.

Yin, R. K Case Study Research: Design and Methods, Beverley Hills, CA: Sage Publications, 1989.

\section{ABOUT THE AUTHOR}

Anita Greenhill continues to carry out interpretive studies exploring the notions of space and virtuality. These research projects are cross disciplinary and bridge the fields of Information Systems, Education, Cultural Studies, Sociology, and Anthropology. Anita can be reached at A.Greenhill@umist.ac.uk. 